UDC $661.123+54.056+534.18$

\title{
INCREASE IN THE YIELD OF CINNAMIC ACIDS DERIVATIVES FROM ECHINACEA AS A RESULT OF WEAK ACOUSTIC EFFECTS
}

\author{
(C) E.M. Ipanova ${ }^{1}$, D.V. Zarembo ${ }^{2}$, D.N. Vedernikov ${ }^{I^{*}}$ \\ ${ }^{1}$ St. Petersburg State Forest Technical University named after S.M. Kirov, \\ Institutsky per., 5, St.-Petersburg, 194021 (Russia), e-mail: Dimitriy-4@yandex.ru \\ ${ }^{2}$ St. Petersburg State Institute of Technology, Moskovsky pr., 26, St.-Petersburg, \\ 190013 (Russia)
}

The article describes the option of intensification extraction process from the Echinacea purpurea. The effect of acoustic exposure (modulation of stretching) on an increase in the yield of extractives during the extraction of Echinaceae herbs with a $40 \%$ aqueous solution of ethanol is discussed.

The extraction results were evaluated by the solid residue, the optical density of the solution. The yield of extractive substances is increased 1.5 times by generating a specific electrical signal in the form of a meander with a certain frequency range $350 \mathrm{kHz}$ and amplitude $3 \mathrm{~V}$. The yield of extractives is calculated on the sum of hydroxycinnamic acids. The best extraction time is determined. The results obtained allow us to hope for a reduction in the preparation time of extracts in the existing production of Echinacea tincture, where $40 \%$ ethanol is used and the infusion time exceeds 2 days. In further work, attention will be focused on finding optimal extraction conditions when using $70 \%$ ethanol and hot water, solvents used in a number of industries. Studying the effect of the solvent on extraction may allow us to get closer to explaining the observed phenomenon.

Keywords: Echinacea purpurea, extraction, $40 \%$ ethanol, acoustic effect.

\section{Introduction}

Echinacea purpurea (L.) Moench is one of the most common and well-known medicinal plants. The popularity of the plant is associated with the high content of biologically active substances and the wide range of drugs from the plant [1]. This species has been traditionally used to treat toothache, intestinal pain, cramps, skin diseases, chronic arthritis and infectious diseases of the upper and lower respiratory tract [2]. Drugs based on Echinacea purpurea (EP) (infusions, tinctures and capsules) are generally used to improve immunity [3]. The greatest therapeutic effect is achieved with at total extraction of all plant substances. The biological activity of individual components is much lower. It is assumed that the immunostimulating properties of E. purpurea drugs are associated with the presence of alkamides, derivatives of caffeic acid and polysaccharides [4, 5]. A number of studies have revealed that alkamides are involved in the immunomodulatory properties of EP extracts in vitro and in vivo [6]. In addition, some Echinacea species contain caffeic acid, which can be used to authenticate and control plant quality. Echinacea is almost exclusively sold as an immune-boosting supplement in the contemporary US market. However, the development of micropropagation, bioreactors and elicitors make it possible to take advantage of other bioactivities. Extensive study demonstrates that EP extracts have antibacterial, antiviral and antifungal activities [7, 8], hypoglycaemic, antioxidant activity [9].

Chicoric and caftaric acids were the major phenolic compounds in coneflower. If purple coneflower tincture is required, then $40 \%$ ethanol is recommended for extraction from roots and flowers, whereby the best extraction of both individual and total analyzed phenolics is achieved. Alcohol tincture from flowers additionally contains anthocyanins, which also has an antioxidative function in human health [10].

\footnotetext{
Ipanova Elizaveta Mikhailovna - student,

e-mail: lisaghost1@gmail.com

The amount of CA even within one species may

Zarembo Daria Viktorovna - Associate Professor, e-mail: ndz@list.ru

Vedernikov Dmitriy Nikolayevich - Professor,

e-mail: Dimitriy-4@yandex.ru vary depending on the age of the plants, the duration of their cultivation and the phase of the vegetation [11]. The antibacterial and cytotoxic activity of EP extracts is solvent dependent [12].
}

\footnotetext{
${ }^{*}$ Corresponding author.
} 
<smiles>O=C(/C=C/c1ccc(O)c(O)c1)O[C@H](C(=O)O)[C@@H](OC(=O)/C=C/c1ccc(O)c(O)c1)C(=O)O</smiles>

chicoric acid<smiles>O=C(/C=C/c1ccc(O)c(O)c1)O[C@@H](C(=O)O)[C@@H](O)C(=O)O</smiles>

caftaric acid

Echinacea presents a myriad of potential health benefits, including anti-inflammatory, anxiolytic and antibiotic activities that have yet to be fully translated into new applications. The distinct chemistry and bioactivity of different Echinacea species and organs, moreover, can lead to interesting and diverse commercial opportunities [13].

It is known that different technologies for preparing tinctures and extracts change the content and ratio of substances and compounds extracted from plant raw materials, as well as their pharmacological activity [14]. EPbased drugs differ in the amount and composition of substances released from the plant, the concentration of ethyl alcohol [15].

Various methods of obtaining tincture are offered $[16,17]$. It is known to produce EP tincture by the following method: ground grass is extracted with ethyl alcohol $40 \%$ at temperature $20-30{ }^{\circ} \mathrm{C}$, infused for $12-24$ hours, then part of extract is drained. The fresh extractant is added to the residue and infusion is repeated for 12-24 hours [18].

The tenso-pulse modulation method uses the conversion of a pulsed electrical signal into an antenna deformation. Acoustic impact, vibration transmitted by deformation of the antenna when creating a short circuit as a result of applying a pulsed signal, can increase heat transfer and mass transfer [19]. The tensile-pulse modulation is a change in the parameters of impulse signals in time or in space. Usually this process is a kind of modulated oscillations, where a sequence of pulses is used as a "bearer" of information [20, 21]. Application of low-energy tensilepulse (acoustic) influence can be used for maximum extraction of extractive substances (ES) from plant raw materials. Earlier it was found that during the extraction of birch bast with an aqueous solution of alkali, weak vibration in-creases the yield of extractives in a narrow range of frequencies and amplitudes set on the generator [22]. The purpose of our work is to determine the conditions of tensile-pulse influence under which there is an increase in the yield of ES from EP when infused in $40 \%$ ethanol at room temperature.

\section{Experimental}

Materials. Dried herb of a perennial cultivated herb Echinacea purpurea (L.) Moench. (EP), collected during the beginning of flowering period. EP collected in 2019 in, Altay Territory. External and microscopic characteristics of raw materials correspond to the description [23]. The relative humidity of the material is $11.8 \%$. The sizes of the particles of materials were determined on sieves. The material consisted of particles of the following: $19 \%$ fraction - 2.5-5.0 mm, 7\% - 2.0-2.5 mm, 31\% - 1.25-2 mm, 9\%- 1.0-1.25 mm, 19\% 0.5-1.0 mm, 8\%-0.3-0.5 mm, 7\% $<0.3 \mathrm{~mm}$.

Extraction conditions. Raw materials weighing about $10 \mathrm{~g}$ were placed in a $100 \mathrm{ml}$ conical flask (1), filled in $70 \mathrm{ml}$ of $40 \%$ of ethyl alcohol. The liquid level was at the top of the material. The scaling process was tested in a $1000 \mathrm{ml}$ flask with added $900 \mathrm{ml}$ of $40 \%$ of ethyl alcohol and $130 \mathrm{~g}$ of materials. A foam stand of $1 \mathrm{~cm}$ height was installed between the flask and the table to avoid external vibration. The electromagnetic generator was short-circuited to a steel clamp - an antenna, mounted on a socket of the flask to perform vibration using electromagneticacoustic conversion. For the experiment, a UTG9002C signal generator was used with the following characteristics: wave shapes: meander, sinus, triangle; Frequency $0.2 \mathrm{~Hz}-2 \mathrm{MHz}$. Accuracy $\pm 1 \%$. Resolution is $1 \mathrm{uHz}$. Amplitude range: from $1 \mathrm{mV}$ to $20 \mathrm{~V}$ post. Accuracy $\pm 5 \%$. Resolution is $0.1 \mathrm{mV}$. The output power is less than $2 \mathrm{~mW}$. Impedance $-50 \Omega$. A meander signal was used to determine optimal exposure conditions, frequencies ranging from 1 to $450 \mathrm{kHz}$ and amplitudes ranging from 2.4 to $3.2 \mathrm{~V}$.

The extraction was carried out for 5 and 24 hours without stirring. Vibration action was carried out throughout the entire period of material extraction. For more complete extraction, repeated extraction was used. 
Analysis of extraction results. The extract was filtered through a pleated paper filter, grade 3 in the end of the process. Solids were determined in the filtrate. To this end, $10 \mathrm{ml}$ of the extract was transferred to a dried weighing bottle and dried to a constant weight. Extractive yield (ES) was estimated based on aliquot size as the ratio of filtrate solids to absolutely dry material. The standard deviation in the determination was $1.5 \%$.

The content of phenolic compounds was also determined by optical density. The resulting extract was diluted 500 times and the optical density of the solution was determined at $322 \mathrm{~nm}$ on a SF-26 spectrophotometer. Optical density was measured at $322 \mathrm{~nm}$. This wavelength is used to estimate the amount of hydroxycinnamic acids derivatives because a maximum is observed at this wavelength (Fig.). Spectrum was obtained on a Shimadzu UV-2401PC spectrophotometer.

The content of the sum of hydroxy-cinnamic acid in terms of the cichoric acid in the liquid extract was calculated by formula [11]:

$$
C_{C A}=\frac{D \cdot V_{2}}{V \cdot 782}
$$

where $C_{C A}$ - hydroxy-cinnamic acids concentration in terms of cichoric acid in solution, $\% ; D$ - the optical density at a maximum of $322 \mathrm{~nm} ; V_{2}$ - volume of diluted solution, $\mathrm{ml}(50 \mathrm{ml}) ; V$ - the volume of sample solution (filtered), $\mathrm{ml}(0.1 \mathrm{ml}) ; 782$ is the specific absorption of cichoric acid in water at $322 \mathrm{~nm}$. The standard deviation in the determination was $1.2 \%$.

The cichoric acid (CA) yield was calculated by the formula:

$$
\text { The yield }{ }_{\mathrm{CA}}=\left(\frac{66.6 \cdot C_{C A}}{m \cdot 100}\right) \cdot 100
$$

where the yield $\mathrm{CA}_{\mathrm{A}}$ - the yield of cichoric acid in \% to a.d.m, $C_{C A}$ - the concentration of hydroxyl-cinnamic acids in terms of cichoric acid in solution, \%; $m$ - mass of absolutely dry EP, g, 66.6 - mass of extract (70 ml with a density of 0.9512 ).

UV-spectrum of EP extract ( $\mathrm{Y}-$ optical density, $\mathrm{X}$ - wavelength in $\mathrm{nm})$

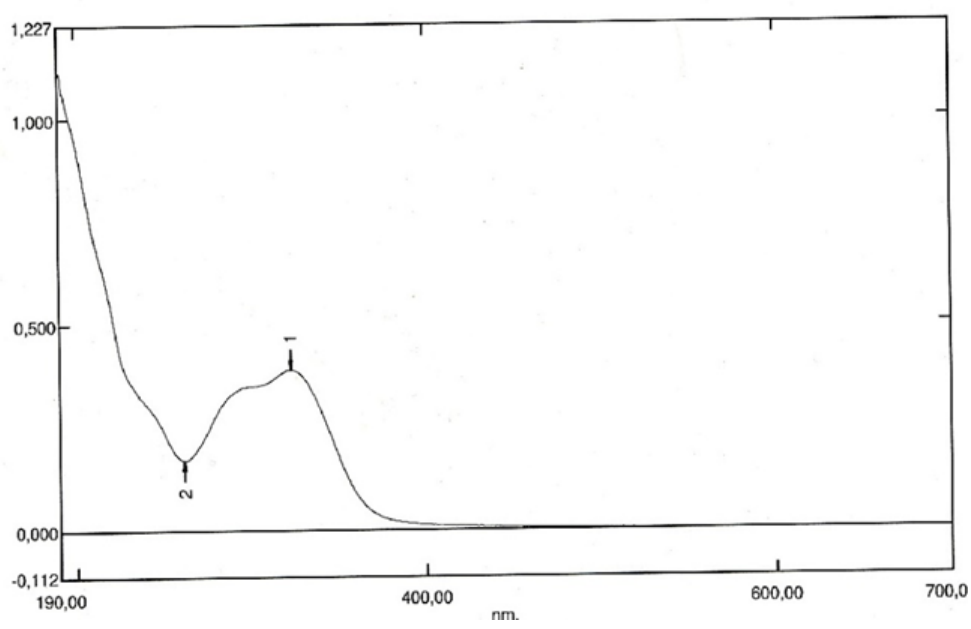

\section{Results and discussion}

The change in the yield of ES and the CA yield (Table 1) occurred upon extraction for 24 hours in the test frequency range (100-400 kHz). The cooking tincture time was selected according to the method [18].

The infusion time was reduced to 5 hours to determine a narrower frequency interval in a shorter time. ES yield and CA yield (Table 2), respectively decreased.

The greatest CA and ES yields are achieved when exposed to vibration with a frequency of $350 \mathrm{kHz}$. The effect was observed with extraction for 24 hours and 5 hours with a frequency change within $2 \mathrm{kHz}$.

Signal amplitude also affects the yield ES (Table 3). 
The greatest ES and CA yields were observed at the generation of vibration when an electromagnetic generator was connected with a frequency of $350 \mathrm{kHz}$ and an amplitude of $3.0 \mathrm{~V}$. The signal amplitude also affects the ES yield.

The experiments were carried out for 10 hours, 14 hours, and 48 hours, where after 5, 7 and 24 hours, respectively, the extractant was replaced to evaluate the effect obtained by extraction of EP according to the procedure [18]. The extracts were combined after two extractions. The ES and CA yields (Table 4) were monitored after the first extraction and in a combined tincture. The exposure frequency is $350 \mathrm{kHz}$, the amplitude is $3.0 \mathrm{~V}$.

The hydroxycinnamic acids yield after 7 hours of infusion was similar to the yield when infused for 24 hours. The use of a tenso-pulse modulation method allows the extraction of EP with $40 \%$ ethanol at room temperature for 14 hours $(2 \times 7)$ instead of 48 hours (2-24). An increase in the scale of the extraction process by a factor of 10 did not lead to a decrease in the ES yield.

Table 1. The yield ES and CA yield at change of processing frequency, time 24 hours, amplitude $2.8 \mathrm{~V}$

\begin{tabular}{l|c|c|c|c|c|c|c|c|c}
\hline Frequency, kHz & - & 100 & 150 & 175 & 200 & 250 & 300 & 350 & 400 \\
\hline The ES yield, \% to a.d.m. & 21.6 & 22.1 & 22.9 & 22.1 & 23.0 & 23.2 & 22.8 & 24.5 & 22.6 \\
\hline The CA yield, \% to a.d.m. & 1.69 & 1,79 & 1.73 & 1.59 & 1.79 & 1.81 & 2.01 & 2.47 & 1.98 \\
\hline
\end{tabular}

Table 2. The yield ES and CA yield at change of processing frequency, time 5 hours, amplitude $2.8 \mathrm{~V}$

\begin{tabular}{l|c|c|c|c|c|c|c|c}
\hline Frequency, kHz & - & 330 & 340 & 349 & 350 & 351 & 360 & 370 \\
\hline The ES yield, \% to a.d.m. & 21.3 & 22.5 & 21.4 & 22.7 & 23.5 & 21.6 & 22.4 & 22.2 \\
\hline The CA yield, \% to a.d.m. & 1.59 & 1.59 & 1.59 & 1.69 & 1.77 & 1.64 & 1.59 & 1.64 \\
\hline
\end{tabular}

Table 3. Influence of signal amplitude on infusion, time $-5 \mathrm{~h}$, frequency $-350 \mathrm{kHz}$

\begin{tabular}{l|c|c|c|c|c|c|c}
\hline Amplitude, V & 2.4 & 2.6 & 2.8 & 2.9 & 3.0 & 3.1 & 3.2 \\
\hline The ES yield, \% to a.d.m. & 22.4 & 23.4 & 23.5 & 23.3 & 23.9 & 22.7 & 21.2 \\
\hline The CA yield, \% to a.d.m. & 1.77 & 1.88 & 1.77 & 1.91 & 1.98 & 1.78 & 1.55 \\
\hline
\end{tabular}

Table 4. The ES and CA yields concentration at different infusion times (frequency $-350 \mathrm{kHz}$, amplitude $3.0 \mathrm{~V})$

\begin{tabular}{l|c|c|c|c|c|c|c}
\hline \multirow{2}{*}{ Extraction time } & \multicolumn{3}{|c|}{$5 \mathrm{~h}$} & \multicolumn{2}{c|}{$7 \mathrm{~h}$} & \multicolumn{2}{c}{$24 \mathrm{~h}$} \\
\cline { 2 - 7 } & $\begin{array}{c}1 \mathrm{st} \text { extrac- } \\
\text { tion }\end{array}$ & $\begin{array}{c}1 \text { st ex- } \\
\text { traction* }\end{array}$ & $\begin{array}{c}\text { Mixture after } \\
\text { the 1 st and 2 } \\
\text { nd extraction }\end{array}$ & $\begin{array}{c}1 \text { st extrac- } \\
\text { tion }\end{array}$ & $\begin{array}{c}\text { Mixture after the } \\
1 \text { st and 2 nd ex- } \\
\text { traction }\end{array}$ & $\begin{array}{c}1 \text { st extrac- } \\
\text { tion }\end{array}$ & $\begin{array}{c}\text { Mixture after } \\
\text { the 1 st and 2 } \\
\text { nd extraction }\end{array}$ \\
\hline $\begin{array}{l}\text { The ES yield, \% } \\
\text { to a.s a.d.m. } \\
\begin{array}{l}\text { The CA yield, \% } \\
\text { to a.d.m. }\end{array}\end{array}$ & 23.9 & 24.1 & 16.3 & 25.1 & 18.1 & 25.3 & 18.2 \\
\hline
\end{tabular}

* - extraction was carried out in a flask of 1 liter

\section{Conclusions}

An increase in the yield of extractive substances was observed under the influence of a tensile pulse with a power of less than $2 \mathrm{~mW}$ in the frequency range $(100-400 \mathrm{kHz})$. The highest ES yield is observed at a frequency of $350 \mathrm{kHz}$ and an amplitude of $3.0 \mathrm{~V}$. The yield of hydroxyl-cinnamic acids increased 1.5 times with acoustic exposure when infused for 24 hours. The ES yield after 5 hours more than after 24 hours without vibration. The ES yield after 5 hours of infusion with the generator connected is greater than after 24 hours without it.

The best time for extraction, provided the maximum yield of hydroxyl-cinnamic acids is achieved by reextraction and subsequent mixing of the two extracts, is 7 hours. During this time, the same hydroxycinnamic acids yield in the extract is obtained as at 24 hours, but without the use of a generator.

\section{References}

1. Simonovich E.I., Goncharova L.Iu., Shimanskaia E.I. Fundamentalnye issledovaniia, 2012, no. 9, pp. 69-72. (in Russ.).

2. Patel T., Crouch A., Dowless K., Freier D. Brain Behav. Immun., 2008, vol 22(4), pp. 39-39. DOI: 10.1016/j.bbi.2008.04.124. 
3. Barnes J., Anderson L.A., Gibbons S., Phillipson J.D. J. Pharm Pharmacol., 2005, vol. 57(8), pp. 929-954. DOI: 10.1211/0022357056127.

4. Bauer R., Wagner H., Farnswort N.R. Econ. and med. plants res., London, 1991, pp. 253-321.

5. Mamchur F.I., Vasilishin A. Khimicheskii sostav i farmakologicheskie osobennosti rastenii roda Echinacea (Asteraceae). [Chemical composition and pharmacological characteristics of plants of the genus Echinacea (Asteraseae)]. Rostov, 2006, 413 p. (in Russ.).

6. Gertsch J., Schoop R., Kuenzle U., Suter A. FEBS Lett., 2004, vol 577(3), pp. 563-569. DOI: 10.1016/j.febslet.2004.10.064.

7. Parsons J.L., Cameron S.I., Harris C.S., Smith M.L. Pharmaceutical Biology, 2018, vol. 56(1), pp. 485-494. DOI: 10.1080/13880209.2018.1501583.

8. Hudson J.B. J. Biomed. Biotechnol., 2012, vol. 2012, pp. 1-16. DOI: 10.1155/2012/769896.

9. Aarland R.C., Bañuelos-Hernández A.E., Fragoso-Serrano M., Del Carmen Sierra-Palacios E., Díaz de LeónSánchez F., Pérez-Flores L.J., Rivera-Cabrera F., Mendoza-Espinoza J.A. Pharm. Biol., 2017, vol. 55, pp.649-656. DOI: $10.1080 / 13880209.2016 .1265989$.

10. Senica, M., Mlinsek G., Veberic R., Mikulic-Petkovsek M. J. Med. Food., 2019, vol. 22(1), pp. 102-108. DOI: 10.1089/jmf.2018.0026.

11. Vainshtein V.A., Kaukhova I.E., Amelina P.S., Koldashova Iu.A., Minina S.A., Ivanova A.V. Razrabotka i registratsiia lekarstvennykh sredstv. 2018, pp. 54-63. (in Russ.).

12. Coelho J., Barros L., Dias M.I., Finimundy T.C., Amaral J.S., Alves M.J., Calhelha R.C. Santos P.F., Ferreira I.C.F.R. Pharmaceuticals, 2020, vol. 13(6), 125. DOI: 10.3390/ph13060125.

13. Parsons J.L., Cameron S.I., Harris C.S., Smith M.L. Pharmaceutical Biology, 2018, vol. 56(1), pp. 485-494. DOI: 10.1080/13880209.2018.1501583.

14. Muravev I.A. Tekhnologiia lekarstv. [Drug technology]. Moscow, 1980, vol. 1-2, 395 p. (in Russ.).

15. Bauer R., Wagner H. Echinacea: handbuch für ärzte, apotheker und andere naturwissenschaftler. Stuttgart, 1990, 182 p.

16. Patent 2567035 (RU). 2015. (in Russ.).

17. Patent 2552919 (RU). 2015. (in Russ.).

18. Patent 2163138 (RU). 2001. (in Russ.).

19. Laine J.E., MacLeod J.M., Bolker H.I., Goring D.A. Pap. Puu., 1977, vol. 59(4a), pp. 235-247.

20. Zarembo V.I., Kolesnikov A.A. Theoretical Foundations of Chemical Engineering, 2006, vol. 40(5), pp. 483-495. DOI: $10.1134 / \mathrm{s} 0040579506050058$

21. Kolesnikov A.A., Zarembo V.I., Demin V.A., Zarembo D.V. Alternativnaya energetika i ekologia, 2011, no. 6, pp. 90 98. (in Russ.).

22. Bobkova E.O., Kostyukevich N.G., Vedernikov D.N., Bobkova E.O. Khimiya Rastitel'nogo Syr'ya, 2019, no. 3, pp. 285-290. DOI: 10.14258/jcprm2019034391.

23. Gosudarstvennaia farmakopeia Rossiiskoi Federatsii. XIII izdanie. [State Pharmacopoeia of the Russian Federation. XIII edition]. Moscow. 2015, vol. 3, 1292 p. (in Russ.).

Received July 10, 2020

Revised December 7, 2020

Accepted February 3, 2021

For citing: Ipanova E.M., Zarembo D.V., Vedernikov D.N. Khimiya Rastitel'nogo Syr'ya, 2021, no. 2, pp. 327-331. (in Russ.). DOI: 10.14258/jcprm.2021028249. 
